\title{
Retraction Note to: Treatment with a brain-selective prodrug of $17 \beta$-estradiol improves cognitive function in Alzheimer's disease mice by regulating klf5-NF-KB pathway
}

\author{
Wenhao Yan ${ }^{1} \mathbb{D} \cdot$ Jun $\mathrm{Wu}^{2} \cdot$ Bo Song $^{3} \cdot$ Qiang Luo $^{1} \cdot$ Yuming $\mathrm{Xu}^{3}$
}

Published online: 16 July 2021

๑) Springer-Verlag GmbH Germany, part of Springer Nature 2021

Retraction Note to: Naunyn-Schmiedeberg's Archives of Pharmacology (2019) 392:879-886 https://doi.org/10.1007/s00210-019-01639-w

The Editor in Chief has retracted this article because of concerns regarding some of the Western blots presented in Figure $3 \mathrm{~A}, 5 \mathrm{~B}$ and $6 \mathrm{~A}$. The authors were not able to provide original raw data. The Editor-in-Chief therefore no longer has confidence in the integrity of the data in this article.

All authors agree to this retraction.

Publisher's note Springer Nature remains neutral with regard to jurisdictional claims in published maps and institutional affiliations.

The original article can be found online at https://doi.org/10.1007/ s00210-019-01639-w.

Yuming $\mathrm{Xu}$

xuyuming@zzu.edu.cn

1 Department of Pediatrics, The First Affiliated Hospital of Zhengzhou University, Zhengzhou 450052, China

2 Department of Neurology, Shenzhen Hospital of Peking University, Shenzhen 518036, China

3 Department of Neurology, The First Affiliated Hospital of Zhengzhou University, Zhengzhou 450002, China 